Ręba Patrycja. Chronic heart failure - health and social problem. Journal of Education, Health and Sport. 2020;10(4):47-54. eISSN 2391-8306. DOI http://dx.doi.org/10.12775/JEHS.2020.10.04.006

https://apcz.umk.pl/czasopisma/index.php/JEHS/article/view/JEHS.2020.10.04.006

https://zenodo.org/record/3745529

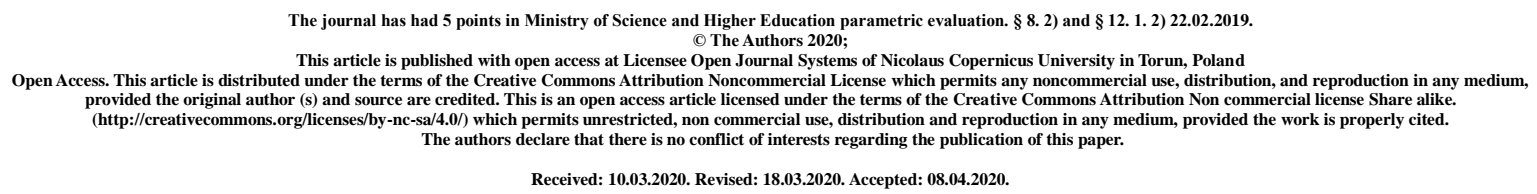

\title{
Chronic heart failure - health and social problem
}

\author{
Patrycja Ręba \\ Faculty of Medicine and Health Sciences, \\ Jan Kochanowski University
}

\begin{abstract}
Admission

Chronic heart failure is a disease entity with a steadily increasing maturity, and the cost of treating patients with this disease is constantly growing.

Over the last decade there has been very significant progress concerning knowledge about this disease. Current diagnosis and treatment can help to inhibit disease development, extending the life and improving its quality. Chronic heart failure is an important medical problem and socioeconomic development of modern Europe. The incidence of PNS European population is estimated at $0.4-2 \%$, which is approx. $6.5-10$ million Europeans.
\end{abstract}

Aim

The aim of the study is to analyze chronic heart failure as a social and health problem.

Material and methods

A review of available literature.

Results

Normally heart failure is divided into left ventricular and right ventricular depending on the defective cell.Quite often distinguished by heart failure, systolic and diastolic. Heart failure can occur as acute or chronic depending on the speed of its development.Some patients with chronic heart failure is observed malnutrition characterized by loss of muscle mass. In this context, it seems important to use a method of establishing the composition of the body, including the state of 
hydration and nutrition in order to monitor any changes. Additional factors affecting the nutritional status of the drug treatment often cause loss of appetite or side effects in the form of gastro intestinal disorders.

\section{Conclusions}

Heart failure is a serious disease with a poor prognosis for the patient. Results of European and American studies show that mortality in patients with CHF is greater than in the case of breast and prostate cancer. It is worth noting that as many as half of patients with severe heart failure die within a year.

\section{Key words: Chronic heart failure; health; social problem}

\section{Introduction}

In recent years there has been a sharp increase in the number of people with chronic heart failure. Increased incidence of hospitalization related to chronic heart failure is a serious medical problem and loss. Chronic heart failure is linked to neurohormonal activation and disorders of control of autonomic nervous system which leads to sodium and water retention, increased potassium excretion, which results in edema or ascites. Neurohormonal activation is also associated with the development of significant changes in body composition. Some patients

Chronic heart failure is observed malnutrition characterized by loss of muscle mass. In this context, it seems important to use a method of establishing the composition of the body, including the state of hydration and nutrition in order to monitor any changes. Additional factors affecting the nutritional status of the drug treatment often cause loss of appetite or side effects in the form of gastro - intestinal disorders. Malnutrition, which occurs in these patients is the negative predictor. Thus reduces the quality of life. Bioelectrical impedance analysis is widely used for studies on nutritional status. Bioelectric impedance of a noninvasive method used widely in people of both sexes, all ages and practically regardless of health status. An efficient way to estimate the individual components of the human body. It is reliable, safe, fast and effective technique for determining the various parameters associated with the distribution of water in the body. Easy to use and repeatability of the results makes bioelectrical impedance analysis is a method that can find broad application in patients with chronic heart failure.

In the literature there are many definitions of chronic heart failure [1]. They typically refer to one or more specific dominant mechanism of this complex. Among them are mentioned, among others, hemodynamic, oxygen consumption and physical performance. A significant part of the definition developed in recent years, takes into account the co-occurrence of the symptoms of PNS in physical examination and fluid retention

Physical examination [2].

The classical definition formulated by Braunwald heart failure as described pathophysiological condition in which the heart is unable to pump blood in sufficient quantities to meet the demand metabolizing tissues or can do so only by increasing the filling pressure [3].

According to the definition given in 2001 by the European Society of Cardiology Chronic heart failure is a clinical syndrome which consists of three key elements. First the 
patient are typical symptoms of heart failure on physical examination such as fatigue, shortness of breath

at rest or during exertion, fatigue, symptoms of fluid retention - stagnation

pulmonary edema or ankle. Secondly helpful in diagnosis appear to be symptoms of certain physical examination: tachycardia, elevated jugular venous pressure, rales over the lungs, pleural transudate, peripheral edema

and hepatomegaly. Thirdly, the undeniable presence of morphological features and functional damage to the heart at rest. It should be taken into account in this group of heart enlargement, heart murmur, increased levels of the natriuretic peptide and cardiac echocardiography [4]. The definition provided by the European Society of Cardiology seems to be a pragmatic and extremely practical.

Normally heart failure is divided into left ventricular and right ventricular depending on the defective cell. This division refers to a set of symptoms associated with the dominance of stasis in the veins of systemic and pulmonary circulation.

Left ventricular failure resulting in stasis of blood in the lungs and a decrease in tissue perfusion. For reasons include: myocardial infarction, hypertension, valvular defects, myocarditis, obesity, alcohol and diabetes. The symptoms of left ventricular failure resulting from pulmonary congestion is shortness of breath which occurs also in a lying position, cough and creaking przypodstawne. Of symptoms related to decreased blood flow through the tissues mentioned weakness, fainting, peripheral cyanosis and nocturia [6, 7].

It is mainly the cause of right heart failure is increased pressure in the pulmonary artery as a result of left ventricular failure, which leads to blood congestion in the tissues, decreased blood flow through the kidneys and lungs, and water, salt retention, fluid retention in the systemic circulation. Right sided heart failure can also occur in isolated form following the initial right ventricular overload

(Eg. Pulmonary hypertension, isolated tricuspid regurgitation). The symptoms of congestive heart failure due to bottlenecks in the tissues include excessive penetration jugular veins, edema of lower limbs, Transudate - pleural effusion, ascites, enlarged liver and spleen, the band liver failure, liver cirrhosis, cardiac [6, 7].

Quite often distinguished by heart failure, systolic and diastolic. Usually observed coexistence of both types of heart failure. Systolic dysfunction characterized by a decline in ejection fraction. While the diastolic heart failure is characterized by an enlarged enddiastolic pressure in the chamber at its respective end-diastolic volume and ejection fraction proper. This type of failure is common in coronary artery disease and myocardial overcapacity. CHF patients with diastolic exhibit clinical symptoms in the test subject, object, and a preserved left ventricular ejection fraction of greater than 40-50\%. In young patients rarely appears in diastolic heart failure and its incidence increases in elderly patients $[8,9,10]$.

Heart failure can occur as acute or chronic depending on the speed of its development.

In chronic heart failure, decreased cardiac output leads to stagnation of blood in the systemic or pulmonary circulation. This type of failure activates a connection Impaired contractility chambers. This is caused by coronary heart disease, myocardial infarction, ventricular overload in response to hypertension 
hypertension or heart failure, dilated cardiomyopathy and falling diastole by hypertrophic cardiomyopathy, restrictive, and pericardial disease. Common symptoms occurring in patients with chronic heart failure include: decreased exercise tolerance, shortness of breath so. orthopnea, cough, nocturia, swelling of the feet, ankles, lumbosacral patients lying. It is worth noting that chronic heart failure is a progressive disease, although it is possible to verify the degree of severity of underlying disease through therapy and a healthy lifestyle $[6,7]$.

Acute heart failure is the sudden appearance of a group of symptoms of impaired contractility of the heart. It occurs as a complication or decompensation of chronic heart failure. It can also occur in people who have never had episodes of cardiac dysfunction. The causes of the acute form of the disease are: excessive supply of water and sodium, improper healing, ischemic heart disease, hypertension, primary course of the disease, arrhythmia, pulmonary embolisms. Symptoms are severe heart failure and pulmonary edema cardiogenic shock, which is characterized by a decrease in blood pressure, oliguria and a reduction in body temperature. Prognosis diagnosed with acute heart failure is assessed as bad. Many patients die due

the priority of the blood supply the organs [11].

The most common classification used to assess the severity of heart failure is NYHA functional classification (New York Heart Association) (Tab. 3.1). It is characterized by simplicity and a high degree of dissemination. It should also include an assessment of distance that the patient is able to overcome and the number of steps, which falls [12].

Tab. 3.1. NYHA functional classification [12]

\begin{tabular}{|c|l|}
\hline \multicolumn{2}{|c|}{ Status defined on the basis of intensification of symptoms and physical activity } \\
\hline class I & $\begin{array}{l}\text { Without limitation of physical activity. Ordinary activity does not cause fatigue, } \\
\text { palpitations or shortness of breath. }\end{array}$ \\
\hline class II & $\begin{array}{l}\text { Slight limitation of physical activity. Comfort at rest, but ordinary physical activity } \\
\text { causes fatigue, palpitation, or dyspnea. }\end{array}$ \\
\hline class III & $\begin{array}{l}\text { Considerable limitation of physical activity. Comfort at rest, but less than average } \\
\text { physical activity causes fatigue, palpitation, or dyspnea. }\end{array}$ \\
\hline class IV & $\begin{array}{l}\text { The inability to perform any physical activity without causing discomfort. Symptoms } \\
\text { of heart failure at rest. After making any physical activity increases discomfort. }\end{array}$ \\
\hline
\end{tabular}

Noteworthy is the classification of heart failure developed in 2001 by the American College of Cardiology / American Heart Association (ACC / AHA) (Tab. 3.2). It takes into account the risk factors and their progression [13].

Tab. 3.2. The phases of heart failure according to the ACC / AHA [13]

\begin{tabular}{|l|l|}
\hline \multicolumn{2}{|c|}{ The phases of heart failure based on the structure and extent of myocardial damage } \\
\hline phase A & $\begin{array}{l}\text { The high risk of developing heart failure. No irregularities identified on the structure } \\
\text { and activity without symptoms and signs. }\end{array}$ \\
\hline phase B & $\begin{array}{l}\text { Developed structural heart disease, which is closely related to the development of heart } \\
\text { failure, but without the signs and symptoms. }\end{array}$ \\
\hline phase C & Symptomatic heart failure due to which it was based structural heart disease. \\
\hline phase D & $\begin{array}{l}\text { Advanced structural heart disease and marked symptoms of heart failure at rest despite } \\
\text { optimal medical therapy. }\end{array}$ \\
\hline
\end{tabular}


Chronic heart failure is a disease entity with a steadily increasing maturity, and the cost of treating patients with this disease is constantly growing.

Over the last decade there has been very significant progress concerning knowledge about this disease. Current diagnosis and treatment can help to inhibit disease development, extending the life and improving its quality.

Chronic heart failure is an important medical problem and socio-economic development of modern Europe. The incidence of PNS European population is estimated at 0.4 - 2\%, which is approx. 6.5 - 10 million Europeans [14]. In Poland, chronic heart failure affects $0.8-1$ million adults [15]. Importantly, the incidence and prevalence of chronic heart failure increases with age. Epidemiological studies conducted in the United States and Western Europe have shown that chronic heart failure affects people over 75 years of age [16]. Of note is the fact that the prevalence increases sharply after the age of 75 , covering $10-20 \%$ of people aged $70-80$ years [15].

It should be noted that among patients with CHF approximately $30-50 \%$ of patients with diastolic CHF. Isolated diastolic PNS often refers patients

the elderly, especially women, who usually have hypertension, left ventricular hypertrophy, obesity and diabetes [17]. With age, the incidence of isolated diastolic PNS growing and it is higher in men [18].

Analyzing the data collected it can be concluded that an increase in the incidence begins

women approx. 5-10 years later than in men. Moreover, the number of men and women undergoing treatment is similar, in contrast to other cardiovascular diseases, in which emerges the male predominance [18].

A study conducted in Framingham informs about the decrease in the annual agerelated incidence of PNS 11\% per decade in men and 17\% among women per decade. Presumably, this is related to an effective therapy of hypertension and a reduced incidence of coronary heart disease [19].

As is clear from the research in Framingham PNS is the most common cause of hypertension (75\%), and coronary heart disease was the cause of heart failure in $50 \%$ of patients. It should be noted that patients with the progress of PNS syntax correlated diabetes and left ventricular hypertrophy. Framingham study shows that in $90 \%$ of cases for the development of PNS responsibility hypertension and coronary heart disease, occurring together or separately [19].

Heart failure is a serious disease with poor prognosis for the patient [16]. Results of European and American studies show that mortality in patients with CHF is greater than in the case of breast and prostate cancer. It is worth noting that as many as half of patients with severe heart failure die within a year [20].

The annual mortality rate depends on the severity of the PNS compatible NYHA functional classification is as follows: Class I, including asymptomatic has a mortality rate of up to $10 \%$; class II, or patients

with minor symptoms during moderate exertion, characterized mortality $10-20 \%$; Class III patients with symptoms constituting PNS during negligible effort shows the mortality 
rate of $20-40 \%$; Class IV is dyspnea at rest, in which mortality ranges from $40-60 \%$ [21].

The analysis of the data shows that the first diagnosis of PNS established in the hospital concerns

$75 \%$ of all diagnoses of this disease. Re-hospitalizations resulting PNS account for about $30 \%$. The mortality rate from this disease in patients treated

in the hospital is $30 \%$ [22].

It is interesting that despite these disappointing data, thanks to modern treatment increases the number of people surviving five years after diagnosis of CHF [23], on the other hand, extending the survival time of patients

with the disease and the aging population [24] generate costs diagnosis

and treatment of this patient group. Pay attention to the fact that the quality of life of patients

PNS is as low as among patients with chronic hepatitis or constantly in people undergoing dialysis. It is believed that this is related to both

with symptoms of the disease as well as the necessity of frequent hospitalizations, which concern not only the economic burden, but especially human suffering. In developed countries, the treatment of chronic heart failure is $1.5-2.5 \%$ of total health expenditure, while the cost of hospitalization is $60-70 \%$ of the total expenditure relating to heart failure. The analysis shows,

that the average cost of treatment of patients with CHF depends on the NYHA functional class.

In Western Europe, ranging from 827 euros in patients belonging to the I-II NYHA class to 14,000 euros for patients in NYHA class IV during the year [15]. 


\section{Literature:}

1. Poole-Wilson PA History, Definition and Classification of Heart Failure. Heart Failure 1 New York: Churchill Livingstone, 1997: 269-77.

2. Heart Failure Society of America. Executive summary: HFSA 2006 Comprehensive Heart Failure Practice Guideline. J Card Fail 2006 12: 10-38.

3. Colucci WS, Braunwald E. Hart Pathophysiology of Failure. In Braunwald E, Zipes DP, Libby P. ed. Heart Disease. Ed. 6 WB Saunders Company, Philadelphia 2001: $503-533$.

4. Task Force for the Diagnosis and Treatment of Chronic Heart Failure, European Society of Cardiology. Remm WJ, Swedberg K. Guidelines for the diagnosis and treatment of chronic heart failure. Eur. Heart J. 2001 22: 1527-1560.

5. Małecka - Massalska T. Assessment of selected parameters of impedance analysis bioelectrical patients with malignant tumors of the head and neck. Publishing house Medical University of Lublin, Lublin, 2012: 23 - 92.

6. H. Chlebus heart failure. National Institute of Medical Publications, Warsaw 1990.

7. Szczeklik A. Internal Diseases. Practical Medicine, Kraków 2005: 311 - 330.

8. Brutsaert DL De Keulenaer GW Diastolic heart failure: a myth. Curr Opin Kardiol 2006 21: 240-8.

9. Caruana L. Petrie MC Davie AP, McMurray JJ For patients with heart Suspected failure and preserved left ventricular systolic function suffer from 'diastolic heart failure 'or from a misdiagnosis? A prospective descriptive study. BMJ 2000 321: $215-8$.

10. De Keulenaer GW Brutsaert DL Diastolic heart failure: a separate disease or selection bias? Threshold. Cardiovasc. Dis. 2007 49: 275 - 83.

11. Nieminen MS, Bohm M. Cowie MR, Drexler H., Filippatos GS, Jondeau G., Hasin Y., Lopez-Sendon J., Mebazaa A., M. Metra, Rhodes, A., Swedberg K., Priori SG, Garcia MA, JJ Blanc, A. Budaj, Cowie MR, Dean V., Deckers, J., Burgos EF Lekakis J., Lindahl B., Mazzotta G., Morais, J. A. Here, Smiseth OA, Garcia MA, Dickstein K, Albuquerque A., Conthe P. Crespo - Leiro M., Ferrari R., Follath F. A. Gavazzi, Janssens U., M. Komajda, Morais, J., Moreno R., M. Singer, S. Singh, Tendera M., K. Thygesen Executive summary of the guidelines on the diagnosis and treatment of acute heart failure: the Task Force on Acute Heart Failure of The European Society of Cardiology. Eur. Heart J. 2005; 26: 384-416.

Criteria 12. The Committee of the New York Heart Association. Diseases of the Heart and Blood Vessels: Nomenclature and Criteriafor Diagnosis. Ed. 6. Mass: Littre Brown Boston 1964: 114.

13. Hunt SA, Baker DW, Chin MH, Cinquegrani MP, AM Feldman, Francis GS, Ganiats TG, Goldstein S., Gregoratos G, Jessup ML, Noble RJ, Packer M, Silver MA, Stevenson LW ACC / AHA guidelines for the evaluation and management of chronic heart failure in the adult: a report of the American College of Cardiology / American Heart Association Task Force on Practice Guidelines (This Committee Revise the 1995 Guidelines for the Evaluation and Management of Heart Failure). 2001. American College of Cardiology Web site. 
Available at: http:////www.acc.org/clinical/guidelines/failure//hf_index.htm

14. Colucci WS, Braunwald E. pathophysiology of heart failure. In Braunwald E.

Banasiak W., G. Opolski, Poloński L. Ed. Diseases of the heart. Volume 1. Urban \& Partner,

Wroclaw, 2007: 493-522.

15. Korewicki J., P. Leszek digger M. Epidemiology and the current state in the range of heart failure management. In: Dubiel JS ed. Heart failure. Via

Medica, Gdańsk 2004: 2 - 64.

16. Kannel W., K. Ho, T. Thom Changing epidemiological features of cardiac failure. Br.

Heart J. 1994, 72 (Suppl. 2): S3-S9.

17. Stewart S., K. MacIntyre, Capewell S., McMurray JJ Heart failure and the aging population: an Increasing burden in the 21 st century? Heart 2003 89: 49 - 53.

18. Rich MW of heart failure in the 21st Century: A cardiogeriatric syndrome. J. Gerontol.

Biol. Sci. Med. 2001 56: M88 - M96.

19. Ho KK, Anderson KM, Kannel WB, Grossman W, Levy D. Survival after onset of congestive heart failure in the Framingham Study. Circulation 1993, 88: 107 - 115.

20. Stewart S., K. MacIntyre, Hole DJ More "malignant" than cancer? 5-years survival Following a first admission with heart failure. Eur. J. Heart Fail. 2001, 3: 315 - 322.

21. Cowie MR, Wood DA, Coats AJS, Thompson SG, Suresh V., Poole-Wilson PA, Sutton GC Survival of patients with a new diagnosis of heart failure: A populationbased study. Heart 2002 83: 505 - 510.

22. Rywik S., Beard G., Jasinski B. Heart failure - mortality and morbidity

Hospital Polish population. Kardiol. Half. 1999 50: 20 - 34.

23. Roger VL, Weston SA, Redfield MM, Hellermann JP-Homan, Killian, J.,

Yawn BP, Jacobsen SJ Trends in heart failure incidence and survival

in a community-based population. JAMA 2004, 292: 344 - 350.

24. Cleland JG, A. Khand, AC Clark, The heart failure epidemic: Exactly how big is it? Eur. Heart J. 2001, 22: 623 - 626. 